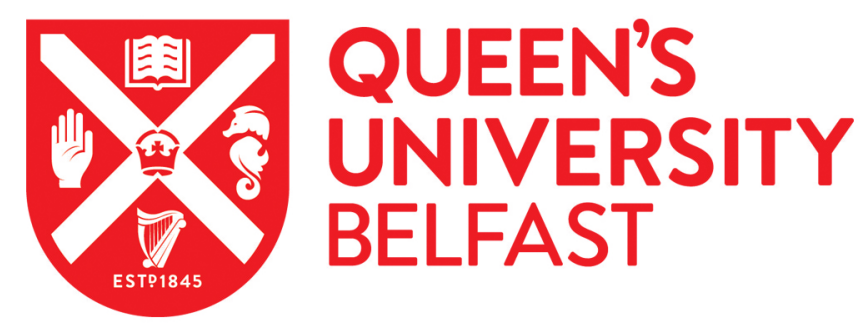

\title{
The effectiveness of cutoff walls to control saltwater intrusion in multi- layered coastal aquifers: Experimental and numerical study
}

Abdoulhalik, A., \& Ahmed, A. A. (2017). The effectiveness of cutoff walls to control saltwater intrusion in multilayered coastal aquifers: Experimental and numerical study. Journal of Environmental Management, 199, 62-72.

Published in:

Journal of Environmental Management

Document Version:

Peer reviewed version

Queen's University Belfast - Research Portal:

Link to publication record in Queen's University Belfast Research Portal

Publisher rights

(c) 2017 Elsevier. This manuscript is distributed under a Creative Commons Attribution-NonCommercial-NoDerivs License

(https://creativecommons.org/licenses/by-nc-nd/4.0/), which permits distribution and reproduction for non-commercial purposes, provided the author and source are cited.

\section{General rights}

Copyright for the publications made accessible via the Queen's University Belfast Research Portal is retained by the author(s) and / or other copyright owners and it is a condition of accessing these publications that users recognise and abide by the legal requirements associated with these rights.

Take down policy

The Research Portal is Queen's institutional repository that provides access to Queen's research output. Every effort has been made to ensure that content in the Research Portal does not infringe any person's rights, or applicable UK laws. If you discover content in the Research Portal that you believe breaches copyright or violates any law, please contact openaccess@qub.ac.uk. 


\title{
The Effectiveness of Cutoff Walls to Control Saltwater Intrusion in Multi-Layered Coastal Aquifers: Experimental and Numerical Study
}

\author{
Antoifi Abdoulhalik ${ }^{1}$ and Ashraf A. Ahmed ${ }^{1, *}$ \\ ${ }^{1}$ School of Natural and Built Environment, Queen's University Belfast, David Keir Building, \\ Stranmillis Road, Belfast, BT95AG, UK
}

\begin{abstract}
The objective of this study was to examine the performance of cutoff walls in controlling saltwater intrusion in stratified heterogeneous coastal aquifers. Numerical and laboratory experiments were completed in laboratory-scale aquifer where the effectiveness of cutoff walls was assessed in three different configurations, including a homogeneous scenario, a stratified aquifer with high $\mathrm{K}$-low $\mathrm{K}$-high $\mathrm{K}$ pattern (case HLH) and another stratified aquifer with low $\mathrm{K}$-high $\mathrm{K}$-low $\mathrm{K}$ pattern (case LHL). The results show that the cutoff wall was effective in reducing the saltwater wedge in all the investigated cases of layered-aquifers with toe length reduction of up to $43 \%$. The wall exhibited more wedge reduction in shallower than steeper hydraulic gradients. However, the soil stratification appeared to lessen the overall performance of the wall compared to the homogeneous case. The aquifer stratification disrupted the flow dynamics, and thus affected the freshwater velocity at the wall opening to various degrees, depending on the layering pattern. The presence of an interlayer of low k (case HLH) inhibited the downward movement of the freshwater towards the wall opening, and thus decreasing the repulsion ability of the wall. Moreover, the presence of an underlying low permeability layer (case LHL) was found to obstruct the freshwater flow in the lower part of the aquifer, thereby slowing down the velocity through the wall opening. Numerical analysis of other layering patterns of monotonically increasing/decreasing permeability from top to bottom showed that the cutoff wall remained effective in repulsing the seawater wedge.
\end{abstract}

\footnotetext{
* Corresponding Author: Email: a.ahmed@qub.ac.uk Tel.: +44(0)2890974015 Fax: +44(0)2890974278
} 
Keywords: Physical barriers; Seawater intrusion control; Coastal aquifers management; Salinization mitigation; Soil heterogeneity; SEAWAT

\section{Introduction}

The contamination of coastal groundwater by oceanic saline water, commonly called Seawater Intrusion (SWI), has been a major problem for coastal populations in many parts of the world, especially where groundwater resources constitute the main source of water supply. While many regions have been impacted by SWI, often as a result of over abstraction (Werner et al., 2013), climate change is expected to exacerbate its detrimental effects in the near future. Climate change related factors include the reduction of the natural recharge into the aquifer (drought) as well as sea level rise. These two factors alter the freshwater discharge into the sea, thereby causing the saline water plume to extend further inland. Considering the forecasting of sea level rise of $0.82 \mathrm{~m}$ towards the end of the century (IPCC, 2014), the implementation of practical countermeasures to mitigate or prevent further SWI and thus allowing more optimal use of fresh groundwater resources becomes of particular importance.

The efforts to preserve the quality of ground waters in coastal zones has yielded the development of various practical engineering solutions affecting the flow hydrodynamic in the aquifer, through physical alteration of a portion of the aquifer and/or groundwater recharge (Werner et al., 2013). Despite being relatively costly, several underground barriers have been constructed in many places in Japan for SWI control, where advanced construction procedures have been deployed allowing noticeable saving in construction cost involved in the implementation of this countermeasure (Luyun Jr, 2010). These are essentially impermeable walls constructed along the seashores, by way of grouting low permeability material to obstruct the inland motion of the saline plume and thus protect groundwater resources. The viability of subsurface barriers has been discussed in several studies (e.g. 
Sugio et al., 1987). Hasan Basri (2001) suggested two methods for optimal design of subsurface barriers to increase the cost-effectiveness of the implementation of this countermeasure. The effectiveness of underground barriers as SWI control method has been explored in several laboratory studies. (e.g. Anwar, 1983; Luyun Jr et al, 2009; Kaleris and Ziogas, 2013; Abdoulhalik et al, 2017).

The two main types of physical barriers include the subsurface dam and the cutoff wall. The first type is set in the lower part of the aquifer while leaving an opening in the upper part for the freshwater discharge, which thereby leads to the physical obstruction of the advancement of the saline water. Luyun Jr. et al. (2009) provided an experimental study on the transient flushing rate of intruded saline water over underground dams of various heights. They concluded that a smaller wall height yielded faster flushing of saline water, as well as a smaller vertical extension of intruding saline plume along the shore.

The second type of barrier covers the upper part of the aquifer, while leaving an opening at the bottom. Anwar (1983) provided an analytical relationship to determine the location of the interface after installation of a cutoff wall, where the coefficients were derived through laboratory experiments. Luyun et al. (2011) investigated the effect of the location and depth of cutoff walls on their overall performance. They concluded that the effectiveness of cutoff walls becomes greater as they are set deeper and closer to the seaside, provided that they are located within the original area of the saline wedge. More recently, Kaleris and Ziogas, (2013) presented an extensive numerical analysis on the effect of cutoff walls in controlling SWI and protecting groundwater withdrawals for an extensive range of parameter combinations that include the wall geometry and hydraulic properties as well as the properties of the aquifer. They provided graphs and empirical equations suitable for field application purposes to evaluate the performance of cutoff walls. Abdoulhalik et al. (2017) suggested a new barrier system denominated mixed physical barrier (MPB), which combined 
a cutoff wall to a semi-permeable dam. This combination promoted upward lifting of saline water toward the seaside and induced considerable saltwater length reduction.

A serious common limitation in the previous studies that investigated the effectiveness of subsurface physical barriers is the assumption of idealised homogeneous and isotropic conditions. The presence of heterogeneity may impact the flow dynamics and solute transport processes to various degrees depending on the scale of the heterogeneity (Werner et al., 2013). For instance, the impact of soil heterogeneities on the freshwater-saltwater interface location was investigated by Dagan and Zeitoun (1998) using the sharp-interface approach. Their results emphasized that disregarding aquifer stratification may lead to misestimating the saltwater intrusion length. Similarly, Lu et al. (2013) presented steady state SWI experiments in layered aquifers with various stratification patterns, and also found a substantially larger saltwater wedge extent in the homogeneous scenario relative to the layered scenarios.

It can be concluded from the literature that all the previous work that investigated the use of physical barriers to control SWI were done for homogeneous media, which is rarely found in real world problems. The heterogeneity of real field sites is inevitable and more common. Therefore, the main purpose of this research was to study the effectiveness of cutoff walls to control SWI in heterogeneous soil formations, which allowed a more realistic assessment of their performance. To the best of our knowledge, this is the first study attempting to experimentally and numerically analyse the effectiveness of cutoff walls on controlling SWI in heterogeneous aquifers. In addition, this study investigated SWI under transient conditions, which was rarely done in previous experimental studies.

Eighteen laboratory experiments ( 6 physical experiments $\times 3$ different hydraulic gradients) were completed to examine the effect of cutoff walls in three different aquifer settings, including a homogeneous scenario (case $\mathrm{H}$ ) for reference purpose, and two stratified aquifers, 
one with high $\mathrm{K}$-low K-high K (case HLH) and the other with low K-high K-low K (case LHL). The experiments were completed in a head-controlled groundwater system, and a recently developed automated image analysis method (Robinson et al., 2015, 2016) was used to derive the key intrusion parameters under transient conditions. The SEAWAT code was adopted to assess the consistency of the experimental results with the numerical predictions and to provide insight on the flow dynamics imposed in each aquifer setting investigated. Sensitivity analysis was also conducted to evaluate the influence of some wall design and aquifer parameters on the overall effectiveness of cutoff walls to control SWI.

\section{Materials and methods}

\subsection{Experimental method}

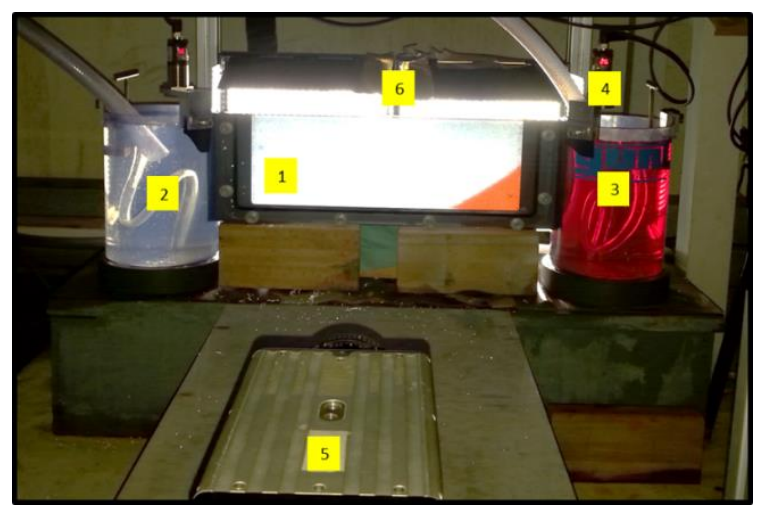

Figure 1 Photograph of the experimental set up; 1) porous media chamber; 2) freshwater reservoir; 3) saltwater reservoir; 4) ultrasonic sensors; 5) high speed camera; 6) LED lights

A laboratory tank of dimension $0.38 \times 0.15 \times 0.01 \mathrm{~m}$ representing a cross section of an unconfined coastal aquifer was used for the experiments (Fig 1). The left reservoir was used to transmit a freshwater flow through the system and a constant saltwater boundary was imposed at the right reservoir. A $200 \mathrm{~L}$ saltwater solution was prepared prior the experiments by dissolving commercial salt into freshwater at a concentration of $36.16 \mathrm{~g} / \mathrm{L}$ to achieve a density of $1025 \mathrm{~kg} / \mathrm{m}^{3}$. The latter was dyed using red food colour at concentration of $0.15 \mathrm{~g} / \mathrm{L}$ to distinguish it from the freshwater. To control the density, a hydrometer (H-B Durac plainform holycarbonate) was used. 
The porous media chamber was filled with glass beads that were packed under saturated conditions to avoid air bubbles development. The beads were packed in successive evensized layers and each layer was carefully compacted. Two LED lights were placed behind the set-up and a light diffuser was fixed to the back of the tank to homogenise the light throughout the porous media. The porous media chamber was joined by two reservoirs at either side providing the head boundary conditions. Two fine mesh acrylic screens were used to separate the porous media chamber from the side reservoirs.

Three different aquifer configurations were analysed in this investigation, including two stratified aquifers (case HLH and case LHL) and homogeneous scenario (case $\mathrm{H}$ ) for reference. The two heterogeneous scenarios were composed of three quasi uniform layers of about $5 \mathrm{~cm}$ height. The case $\mathrm{H}$ was performed using glass beads of mean diameter $1325 \mu \mathrm{m}$ and the low K layer was simulated using glass beads of mean diameter $780 \mu \mathrm{m}$. All beads where purchased from Whitehouse Scientific $®$. The average hydraulic conductivity of each type of beads was previously measured within the experimental flow tank using Darcy's law and was estimated at $1.8 \times 10^{-2} \mathrm{~m} / \mathrm{s}$ and $6 \times 10^{-3} \mathrm{~m} / \mathrm{s}$ for the $1325 \mu \mathrm{m}$ and $780 \mu \mathrm{m}$ beads, respectively.
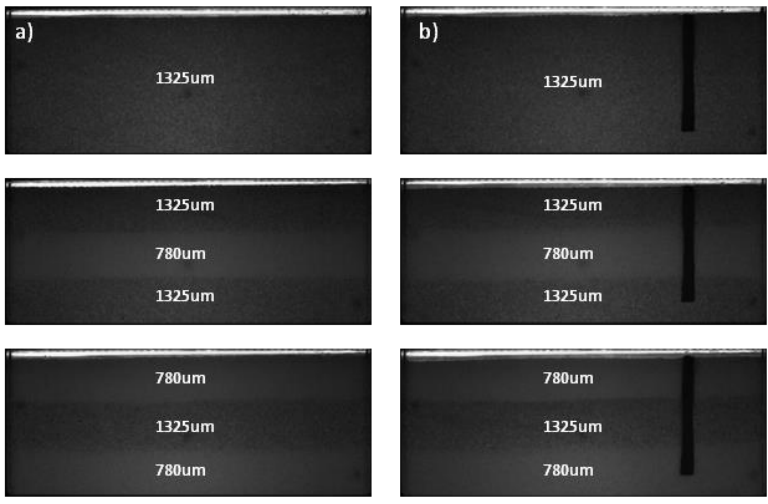

Figure 2 Investigated scenarios: case H (top); case HLH (middle) and case LHL (bottom);

a) Base cases b) Cutoff wall cases

Fig 2 presents the photographs of all the investigated cases. In all, two sets of experiments were completed. The first set represented the saltwater intrusion scenarios occurring in each aquifer setting prior to the installation of the barrier, considered as base cases. In the second 
set, a cutoff wall was installed into the system. The cutoff wall was made of impermeable material (plasticine) and was installed prior to the siphoning and packing of the beads in the tank (Abdoulhalik et al., 2017). To ensure that the cutoff wall was located within the original zone of the saltwater wedge for good effectiveness (Luyun et al., 2011), the cutoff wall was designed based on the delineation of the saltwater wedge in the homogeneous scenario (case $\mathrm{H})$. The cutoff wall was placed prior to the beads packing at $6.8 \mathrm{~cm}$ from the seaside boundary with a penetration depth such that an opening of $2.8 \mathrm{~cm}$ was left between the tip of the wall and the bottom of the tank, considering that cutoff walls are generally located within a distance of twice the aquifer height from the coastline or closer (Allow, 2012; Japan Green Resources Agency, 2004).

The effectiveness of the cutoff wall was expressed here in terms of the percentage reduction of the intrusion length relative to the base case scenario $R=\left(T L_{0}-T L_{b}\right) / T L_{0}$, where $T L_{0}$ and $\mathrm{TL}_{\mathrm{b}}$ are the intrusion length before and after the wall installation, respectively (Kaleris and Ziogas, 2013; Abdoulhalik et al., 2017).

\subsection{Experimental procedure}

To allow the determination the key SWI intrusion parameters under transient conditions, each experimental test was preceded by a calibration procedure. This calibration was required to correlate the light intensity of the recorded images to the salt concentration. This was achieved by flushing of the porous media with saltwater solutions at various known concentrations, and recording the light intensity of every single pixel for every concentration used. More details on the methodology can be found in Robinson et al. (2015). A MATLAB code was then used to obtain the intensity-concentration parameters. The images recorded over the course of the experiment could then be analysed to calculate the toe length (TL) of 
the saltwater wedge, which corresponds to the distance between the $50 \%$ concentration isoline and the saltwater boundary along the bottom boundary.

At the start of each experiment, a saltwater level of $12.97 \mathrm{~cm}$ was imposed while the freshwater level was set high enough to allow the entire porous media to remain fully saturated with freshwater. Ultrasonic sensors (Microsonic - mic+25/DIU/TC) were used to control the freshwater and saltwater levels with $\pm 0.2 \mathrm{~mm}$ accuracy. Excess amount of saltwater solution was constantly supplied into the saltwater reservoir to ensure that any possible freshwater floating at the surface was flushed out. The experiment was then initiad upon stabilisation of the density measurements. Various hydraulic gradients were applied to the system to simulate changes in the hydrological conditions. This was done by varying the freshwater level such that to impose head differences $\mathrm{dh}=6 \mathrm{~mm}, 5.2 \mathrm{~mm}$ and $4.4 \mathrm{~mm}$, corresponding to hydraulic gradients of $0.0158,0.0137$ and 0.0116 , respectively. These values are within the range of gradients values commonly used in similar previous laboratory studies (Goswami and Clement, 2007; Chang and Clement, 2012; Abdoulhalik et al., 2017).

\subsection{Numerical method and procedure}

The MODFLOW family variable density flow code SEAWAT was used to assess the consistency of the experimental data with the numerical predictions, provide better explanations of the experimental results and further explore the performance of cutoff walls for various parameter combinations. The numerical model consisted in a rectangular domain of dimension $38 \times 14 \mathrm{~cm}$ uniformly discretized using a size mesh of $0.2 \mathrm{~cm}$. The longitudinal and transversal dispersivity were estimated after trial and error process and were eventually estimated at $0.1 \mathrm{~cm}$ and $0.05 \mathrm{~cm}$, respectively. These values remain within the range of dispersivity values reported in Abarca and Clement (2009). The dispersivity and element dimensions provided numerical stability by satisfying the Peclet number criterion (Voss and 
Souza, 1987). Densities of the freshwater and saltwater were $1000 \mathrm{~kg} / \mathrm{m}^{3}$ and $1025 \mathrm{~kg} / \mathrm{m}^{3}$, respectively. A concentration of $36.16 \mathrm{~g} / \mathrm{L}$ was used for the seawater boundary, corresponding to the amount of salt required to prepare the saltwater solution. Hydrostatic pressure conditions were applied at both the freshwater boundary $(\mathrm{C}=0 \%)$ and the coastal saltwater boundary $(\mathrm{C}=100 \%)$.

The simulation procedures of the base cases and the cutoff wall cases were similar. The simulation of the cutoff wall was done by rendering the cells occupied by the wall as inactive in the models. In the initial condition, the numerical model was that of a fully fresh aquifer. Three transient stress periods were performed, where the head differences $\mathrm{dh}=6 \mathrm{~mm}, 5.2$ $\mathrm{mm}$ and $4.4 \mathrm{~mm}$ were successively imposed in the first, second and third stress period, respectively. Every stress period lasted for $50 \mathrm{~min}$ for all the simulations, with a time step of 30s. In the first stress period $(\mathrm{t}=0-50 \mathrm{~min})$, the freshwater and saltwater boundary were set at $13.57 \mathrm{~cm}$ and $12.97 \mathrm{~cm}$, respectively, which allowed the saltwater to enter into the model domain. In the two remaining stress periods, the freshwater level was dropped down to 13.49 $\mathrm{cm}(\mathrm{t}=50-100 \mathrm{~min})$ and $13.41 \mathrm{~cm}(\mathrm{t}=100-150 \mathrm{~min})$.

\section{Results and discussion}

Saltwater intrusion dynamics was first analysed within each aquifer setting prior to the installation of the barrier, to examine of the performance of cutoff walls and attempt to better understand the flow dynamics and solute transport associated to each layering pattern. The concentration colour maps of the base cases are presented in Fig 3. The drop of the freshwater level to $13.57 \mathrm{~cm}$ generated a disturbance to the equilibrium of the system allowing the saline water to enter the system and form a saltwater wedge in the lower right corner. The further decrement of the head difference to $5.2 \mathrm{~mm}$ and $4.4 \mathrm{~mm}$ led to further reduction of the hydraulic forces, allowing the buoyancy forces to enforce the saltwater 
wedge deeper into the system. A summary of the experimental toe length values recorded in the base case is presented in table 1 . The data show that net increase of the saltwater intrusion length resulting from a head decrement of $1.6 \mathrm{~mm}$ (from $\mathrm{dh}=6 \mathrm{~mm}$ to $\mathrm{dh}=4.4 \mathrm{~mm}$ ) was $8.72 \mathrm{~cm}, 8.90 \mathrm{~cm}$ and $7.19 \mathrm{~cm}$ in cases $\mathrm{H}, \mathrm{HLH}$, and LHL respectively.
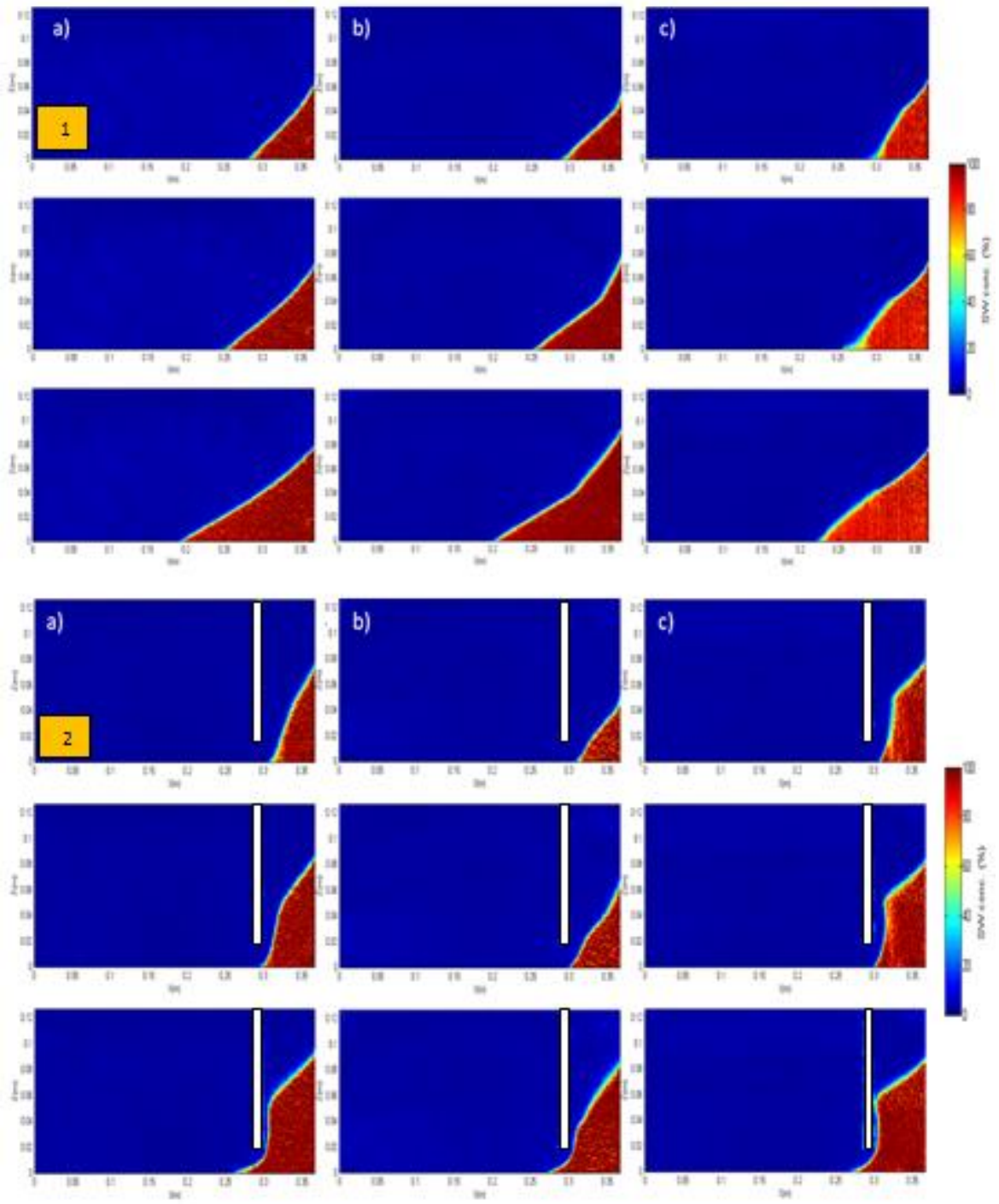

Figure 3 Concentration colour maps of the 1) bases cases (prior to wall installation) and 2) cutoff wall cases; a) case H; b) case HLH and c) case LHL. From top to bottom, $\mathrm{dh}=6,5.2$, and $4.4 \mathrm{~mm}$ 
Table 1 Experimental toe length values in the base cases

\begin{tabular}{|c|c|c|c|}
\hline Head difference & Case H & Case HLH & Case LHL \\
\hline $\boldsymbol{d} \boldsymbol{h}=\mathbf{6} \mathbf{~ m m}$ & $8.4 \mathrm{~cm}$ & $7.4 \mathrm{~cm}$ & $6.9 \mathrm{~cm}$ \\
\hline $\boldsymbol{d} \boldsymbol{h}=\mathbf{5 . 2} \mathbf{m m}$ & $11.7 \mathrm{~cm}$ & $11.2 \mathrm{~cm}$ & $10.4 \mathrm{~cm}$ \\
\hline $\boldsymbol{d} \boldsymbol{h}=\mathbf{4 . 4} \mathbf{m m}$ & $17.2 \mathrm{~cm}$ & $16.3 \mathrm{~cm}$ & $14.1 \mathrm{~cm}$ \\
\hline
\end{tabular}

The data show that the presence of stratification induced the seaward retreat of the saltwater wedge associated with a substantial distortion of the freshwater-saltwater interface, for all the hydraulic gradients tested. The seaward shifting of the interface observed in case LHL compared to the homogeneous scenario was due to the decrement of the buoyancy forces as the saline water is forced to flow through the finer beads, where dispersion and diffusion effects are relatively higher and tend thus to weaken density contrast effects. In case HLH, the middle layer of low $\mathrm{K}$ enhances the freshwater flow in both the upper and lower parts of the aquifer, thereby causing also the seaward retreat of the interface, albeit the freshwater flowing in the top part of the system has little contribution in repulsing the saltwater wedge, but rather flows mostly above the wedge towards the outlet. These observations are in good agreement with the observation reported by Lu et al. (2013), where similar heterogeneous soil settings were investigated at steady-state condition for single head boundary condition.

After wall installation, one may, at first glance, readily observe that the cutoff wall induced considerable repulsion of the saltwater wedge in all the investigated cases (Fig 3). As expected, the cutoff wall disrupted the normal flow dynamics and forced the freshwater to flow downwards through the small opening with substantially higher velocity, resulting in the consequent repulsion of the saline water (Abdoulhalik et al, 2017). It is interesting to note the noticeable distortion of the overall shape of the wedge exhibited in the different layered configurations. The inward dipping freshwater-saltwater interface observed in case HLH 
relative to the homogeneous case suggests that the seaward freshwater flow was relatively greater in the former than in the latter. By contrast, the outward dipping interface observed in case LHL suggests here that the opposition force of the flow was relatively lowered compared to the homogeneous case.

Table 2 Experimental toe length and associated reduction values in the cutoff cases

\begin{tabular}{|c|c|c|c|c|c|c|}
\hline \multirow{2}{*}{ Head difference } & \multicolumn{2}{|c|}{ Case H } & \multicolumn{2}{c|}{ Case HLH } & \multicolumn{2}{c|}{ Case LHL } \\
\cline { 2 - 7 } & $\mathrm{TL}$ & $\mathrm{R}$ & $\mathrm{TL}$ & $\mathrm{R}$ & $\mathrm{TL}$ & $\mathrm{R}$ \\
\hline $\boldsymbol{d} \boldsymbol{h}=\mathbf{6} \mathbf{m m}$ & $6 \mathrm{~cm}$ & $29.5 \%$ & $5.6 \mathrm{~cm}$ & $25.1 \%$ & $6 \mathrm{~cm}$ & $13.9 \%$ \\
\hline $\boldsymbol{d} \boldsymbol{h}=\mathbf{5 . 2} \mathbf{m m}$ & $7.1 \mathrm{~cm}$ & $39.7 \%$ & $6.8 \mathrm{~cm}$ & $38.9 \%$ & $6.7 \mathrm{~cm}$ & $35.6 \%$ \\
\hline $\boldsymbol{d} \boldsymbol{h}=\mathbf{4 . 4} \mathbf{m m}$ & $9.71 \mathrm{~cm}$ & $43.4 \%$ & $9.34 \mathrm{~cm}$ & $42.8 \%$ & $9.44 \mathrm{~cm}$ & $33.1 \%$ \\
\hline
\end{tabular}

The toe length data along with the associated saltwater percentage reductions achieved by the cutoff wall are shown in table 2 . The data show that the presence of layer stratifications generally lowered the effectiveness of the cutoll wall. In case HLH, the seaward shifting caused by the low $\mathrm{K}$ layer in the middle part of the system prior wall installation induced a reduction of the difference $T L_{0}-T L_{b}$, whereas $T L_{b}$. remains nearly the similar (limited at the position of the wall). Likewise, in case LHL the effectiveness of the cutoff wall was even more reduced, given that the shifting observed prior to wall installation was even greater in this configuration. In addition, the flow velocity through the opening of the wall may also be reduced by the underlying low $\mathrm{K}$ layer, which also contributes in reducing the effectiveness of the cutoff walls in such setting. This will be further supported by the maps of the flow velocity provided below. These results nonetheless show the workability of cutoff walls in heterogeneous layered aquifer systems in preventing SWI, but demonstrate that that neglecting the existence of stratification pattern by assuming perfect homogeneous conditions may lead to erroneous estimation of the wall performance. 
The numerical toe length results of the three investigated scenarios are shown in Fig 4. The transient experimental toe lengths in the base cases were reasonably well predicted by the SEAWAT model in the three scenarios, albeit the toe motion was at some point slightly over predicted. Likewise, the simulation results for the cutoff wall experiments yielded perfect agreement with the experimental data. The numerical model confirmed that the cutoff wall was effective in retaining the saline water on the seaward side of the wall for all the head differences tested and in all the investigated configurations, in agreement with the experimental observations.

To better understand the flow dynamics imposed by the layer stratification prior and post to installation of the cut wall, a flow velocity analysis was completed for each scenario (Fig 5). As expected, the magnitude of the flow velocity vectors was relatively even throughout the model domain, reaching maximum values when freshwater exiting the sytem in the top right part of the model domain and very low values within the saltwater wedge in the homogenous scenario, which agrees with results of Chang and Clement (2012). The decrement of the hydaulic gradient, obviously, led to a decrease of the freshwater flux transmitted to the system, manifested by velocity vectors of lower magnitude, which can clearly be seen in the gradual decreasing of red area in the top right part of the model, utlimately leading to further horizontal and veritcal extension of the saltwater wedge. In the cutoff case, this well homogeneized freshwater flow is driven downward towards the reduced cross section of the opening below the wall, thereby causing a significant increase of the flow velocity through the opening, which decreases with as the hydraulic gradient becomes smaller or shallaower. 

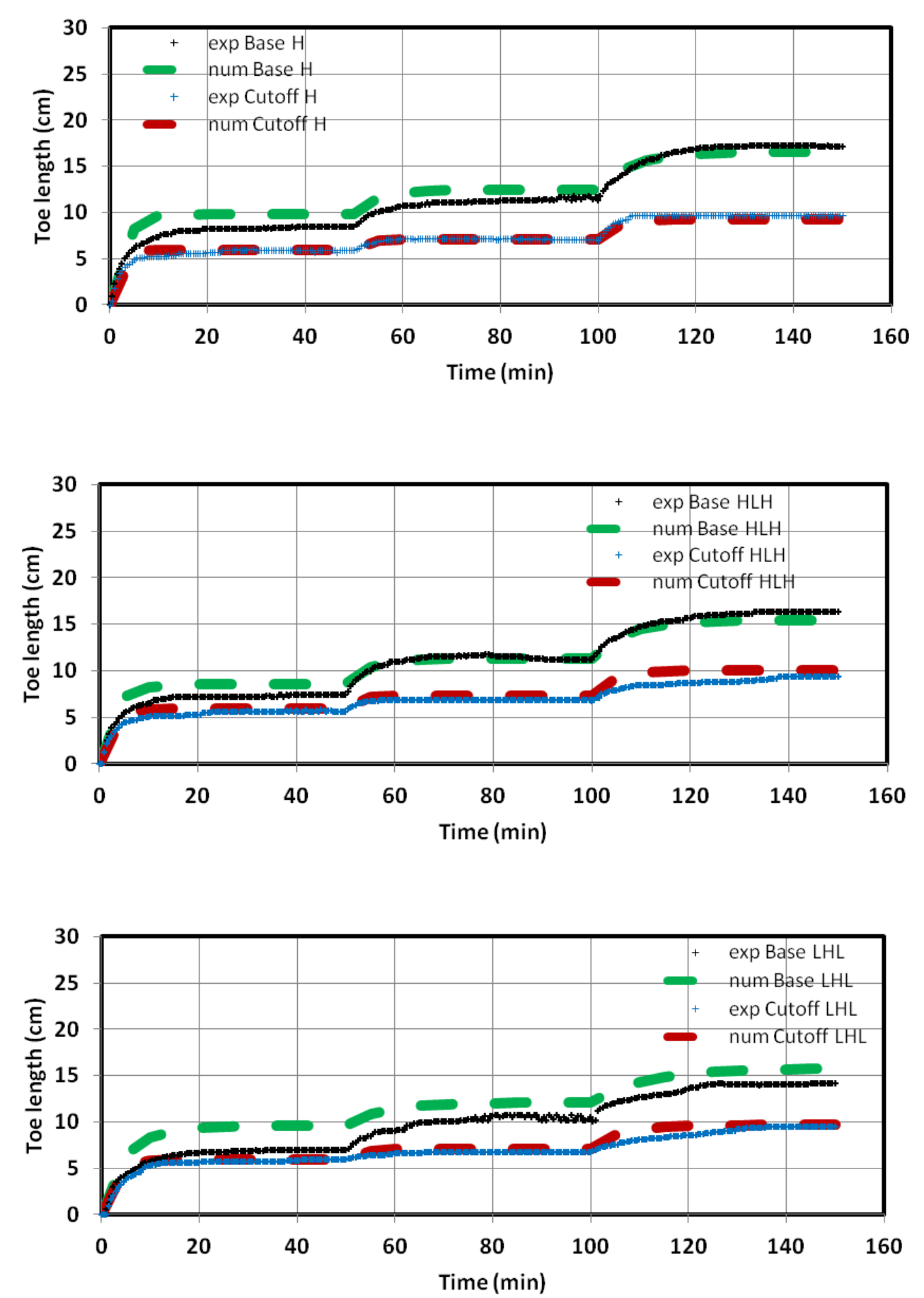

Figure 4 Comparison between transient experimental and numerical toe length data in the base and cutoff wall cases; case $\mathrm{H}$ (top); case HLH (middle) and case LHL (bottom) 

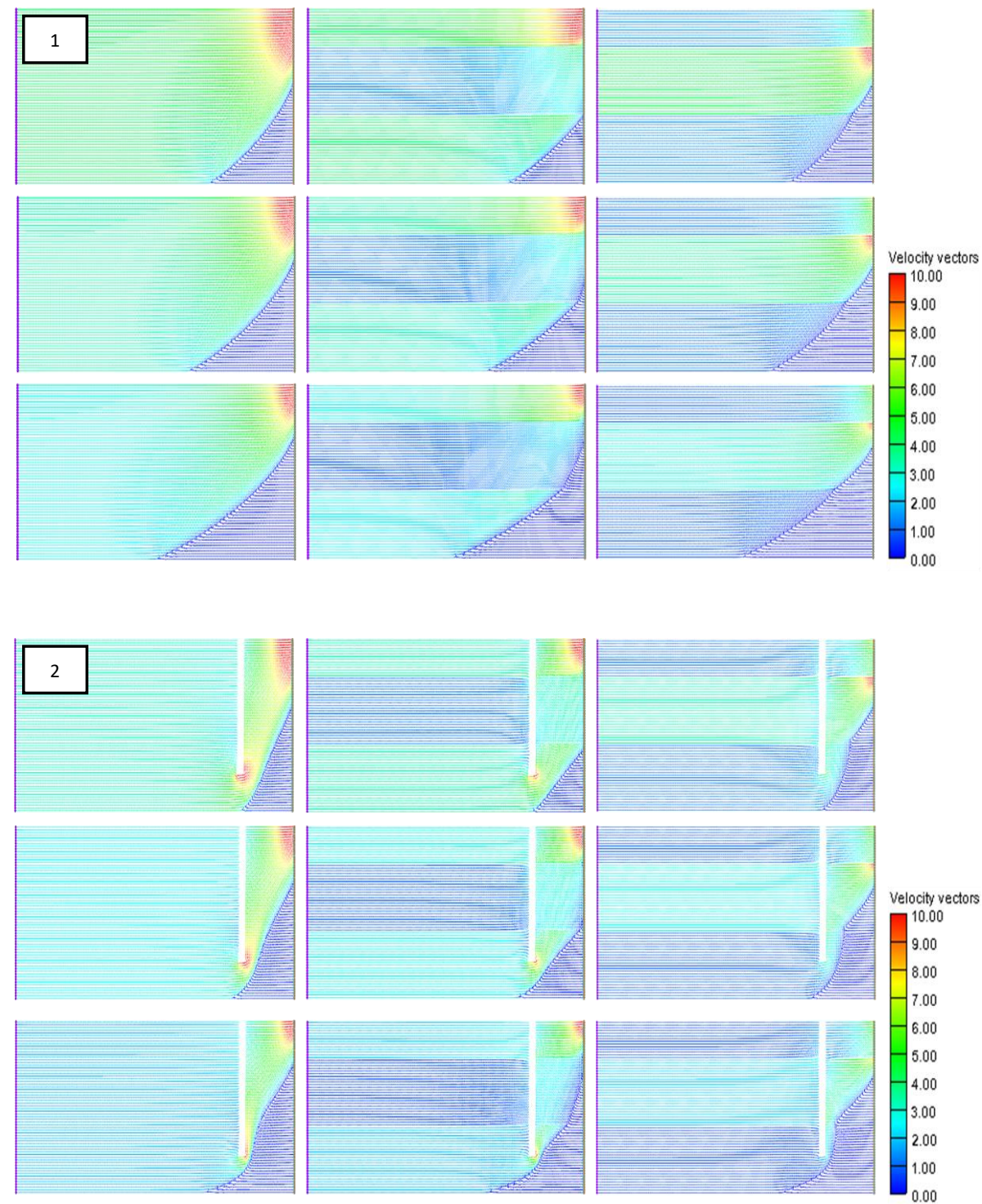

Figure 5 Flow velocity field in 1) the base and 2) cutoff wall cases; (left) case H; (middle) case HLH and (right) case LHL. From top to bottom, $\mathrm{dh}=6 \mathrm{~mm}, 5.2 \mathrm{~mm}$ and $4.4 \mathrm{~mm}$. The velocity vectors are in $\mathrm{cm} / \mathrm{min}$.

In case HLH, the magnitude of the high flow velocitiy vectors was low through the interlayer of low $\mathrm{K}$, as expected, causing the confinement of the flow in the upper and lower parts of the aquifer. After cutoff wall installation, the middle low K layer slows down the downward movement of the freshwater toward the bottom layer and hence the flow velocity through the opening is reduced. This can clearly be seen in the figure where the magnitude of the 
velocity vectors through the opening in the HLH case is smaller than that of the homogeneous scenario.

In case LHL, the high velocity vectors are confined into the higher permeablity zone in the middle part of the aquifer due to the presence of both the overlying and underlying low $\mathrm{K}$ layers. Most of the freshwater flow exits below the bottom boundary of the overlying low $\mathrm{K}$ layer where the magnitude of the velocity vectors is the highest. After the cutoff wall installation, the downard movement of the freshwater imposed by the cutoff wall was partly inhibited by the underlying low $\mathrm{K}$ layer, yielding in a substantial decrease of the magnitude of the flow velocity through the wall opening.

While the saltwater intrusion process is primarily controlled by the freshwater flow through the aquifer (Chang and Clement, 2012; Ketabchi et al., 2016), the results demonstrate that the presence of the layers of various permeability substantially disrupt the natural flow dynamics, thereby strongly affecting the response of the saline water wedge to various degrees, depending on the layer stratification pattern. Specifically, the presence of layers that have relatively low permeability may induce a "channelling" of freshwater flow preferably towards the higher permeability layers, which affect both horizontal and vertical extension of the saltwater wedge and the associated distortion of the freshwater-saltwater interface.

Two additional layering setting were investigated to have more insights on how the soil stratification dissrupts the flow dynamics in heterogenous aquifers before and after wall installation. Fig 6 shows the flow velocity field of two additional layer settings, one with an monotonically increasing hydraulic conductivity from top to bottom referred to as case I and the other with monotonically decreasing hydraulic conductivity referred to as case D. The highest and lowest hydraulic conductivity values in case I and case D corresponded to those of the previous cases $(108 \mathrm{~cm} / \mathrm{min}$ and $36 \mathrm{~cm} / \mathrm{min})$, and the middle layer was set to $85 \mathrm{~cm} / \mathrm{min}$ 
(corresponding to the hydraulic conductivity of other beads size used in our lab). Therefore, the hydraulic condictivity values were $36-85-108 \mathrm{~cm} / \mathrm{min} 108-85-36 \mathrm{~cm} / \mathrm{min}$ in case I and case $\mathrm{D}$ respectively.

In case $\mathrm{I}$, the overlying layer of low $\mathrm{K}$, again, drives the freshwater flow in the lower part of the aquifer facing the saltwater wedge before it exits the system on the top corner of the middle layer, at high velocity. The magnitude of the flow velocity vectors at the tip of wall is significantly relatively higher in this case. By contrast, in case $\mathrm{D}$ the presence of the underlying low $\mathrm{K}$ layer redistributes the flow mainly in the upper part of the system, especially in the top layer where it is the highest, through which most of the freshwater rapidly exits the system without affecting substantially the wedge, which explains the faster horizontal and vertical intrusion of the saltwater wedge, compared to the preceding scenario. The magnitude of the flow velocity vectors at the tip of wall is significantly smaller in this case, allowing more building of saline plume on the seaward side of the wall. Nonetheless, the results demonstrate that the length of the saltwater wedge was also noticeably reduced by the cutoff in these extra heterogeneous settings, for all the hydraulic gradient considered.

\section{Sensitivity Analysis}

Additional simulations were then performed to examine the influence of various relevant parameters on the effect of cutoff walls in stratified coastal aquifer. The stratified case HLH will be considered in this section, considering the cutoff wall relatively less effective in case LHL, in light of the above an results. Also, the simulation was solely performed for $\mathrm{dh}=4.4$ mm which produced the extreme SWI scenario considered in this study. The parameters assessed in this section include the properties of the middle low $\mathrm{K}$ layer, the wall design parameters and the saltwater density. 

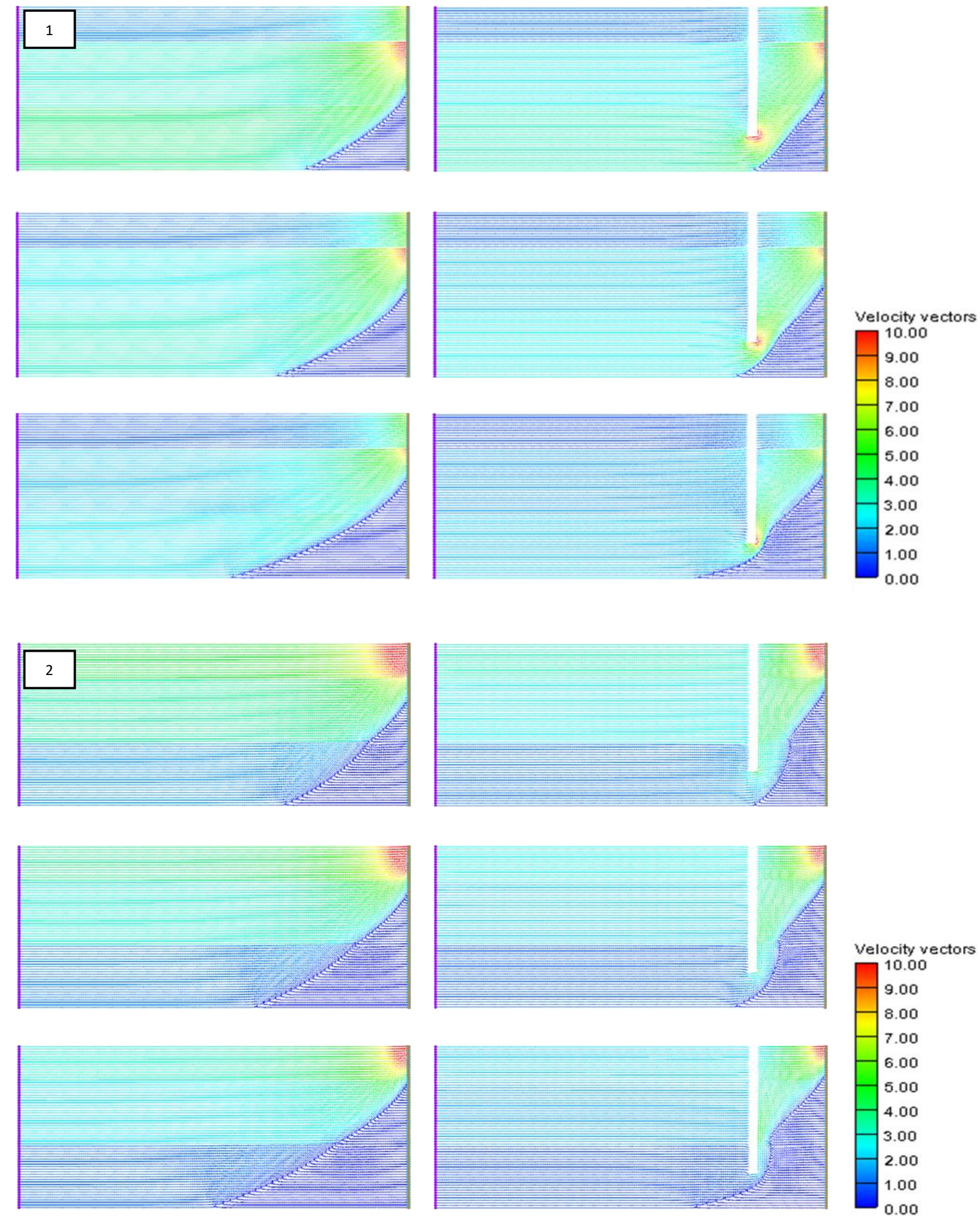

Figure 6 Flow velocity field in the additional cases; 1) case I; 2) case D; (left) base cases, (right) cutoff case. From top to bottom, $d h=6 \mathrm{~mm}, 5.2 \mathrm{~mm}$ and $4.4 \mathrm{~mm}$. The velocity vectors are in $\mathrm{cm} / \mathrm{min}$. 


\section{Sensitivity to wall location and opening size}
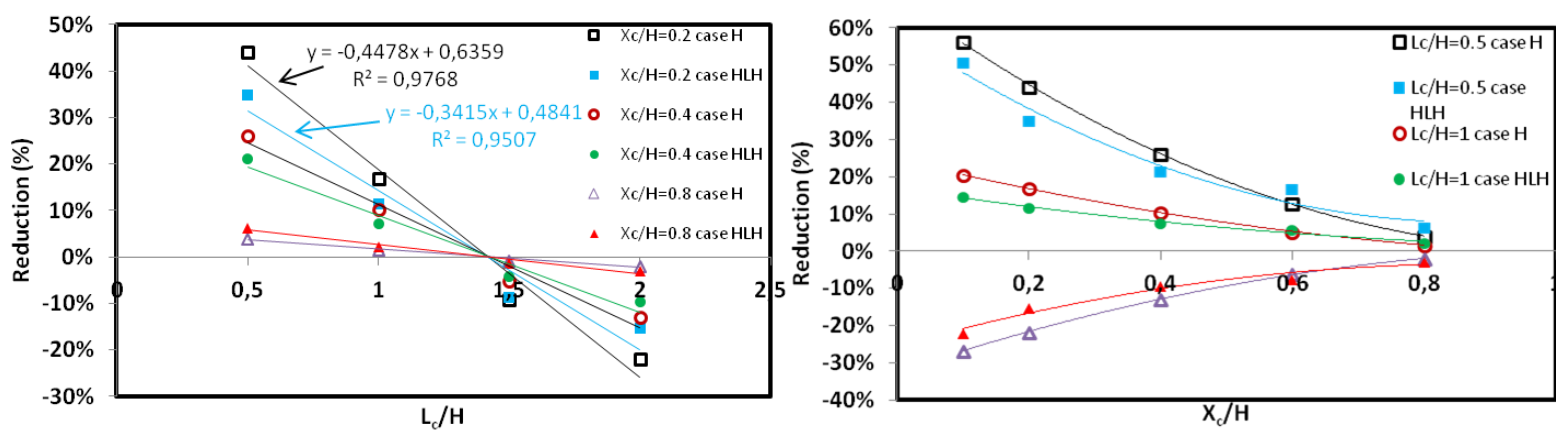

Figure 7 Sensitivity of the reduction to the wall location (left) and to the wall opening size (right)

The effect of the geometrical design parameters of the wall, namely the wall location and depth, on the effectiveness of cutoff wall was first investigated. The location of the wall was characterised by the dimensionless ratio $\mathrm{L}_{c} / \mathrm{H}$, where $\mathrm{L}_{\mathrm{c}}$ is the distance between the wall and the coastline and $\mathrm{H}$ is the saturated aquifer thickness $(\mathrm{H}=13.6 \mathrm{~cm})$. The location of the wall was investigated for four different ratios $\mathrm{L}_{\mathrm{c}} / \mathrm{H}=0.5,1,1.5$ and 2 . These values are within the typical range of dimensionless distance for cutoff wall installation in practical applications (Japan Green Resources Agency, 2004).

The reduction achieved by the cutoff wall increases with decreasing the distance from the coastline, with lower rate of increase in the presence of the low K layer (Fig 7). The simulation was performed for three different wall opening sizes, namely $\mathrm{X}_{\mathrm{c}} / \mathrm{H}=0.2,0.4,0.8$, where the tip of the wall was located below, within and above the low K layer, respectively. For $\mathrm{L}_{\mathrm{c}} / \mathrm{H}<1.4$, the reduction values were smaller in the heterogeneous scenario, indicating that the effectiveness of the cutoff wall was lower under the presence of the low $\mathrm{K}$ layer than in the homogeneous scenario, for equivalent wall location. This is because without the cutoff wall, the low K layer causes the original length and thickness of the wedge to decrease. Thus, the saltwater wedge is less squeezed by the cutoff wall in the presence of the low K layer. As 
the opening becomes wider, the squeezing effect applied by the wall weakens gradually and the effect of the low $\mathrm{k}$ layer becomes smaller.

For $\mathrm{L}_{\mathrm{c}} / \mathrm{H}>1.4$, the reduction becomes negative since at such distance, the cutoff wall is located outside the original area of the saltwater wedge. In such situation, the cutoff wall essentially prevents the freshwater from repulsing the saltwater wedge (Luyun et al, 2011). Hence, given that the reduction is higher in case HLH, the results implies that that adverse effect was reduced under the presence of the low $\mathrm{K}$ layer. The results show that in both scenarios, a simple linear relationship of type $R=-a\left(L_{c} / H\right)+b$ could be derived, where a and $b$ are the regression coefficients (see equation for $X_{c} / H=0.2$ in figure, where $a$, and $b$ are inherent to the present system). The strong linearity of the correlation is manifested by the high coefficient of determination $\mathrm{R}^{2}$ exhibited in all cases. While Luyun et al. (2011) presented similar conclusion for homogeneous systems, the present results extend the applicability of their findings to cases where a low $\mathrm{K}$ layer is incorporated into an aquifer system.

The depth of the wall was expressed as a function of the opening ratio $\mathrm{X}_{\mathrm{c}} / \mathrm{H}$, where $\mathrm{X}_{\mathrm{c}}$ is the wall opening size. The influence of the depth of the wall was investigated for various opening ratios $\mathrm{X}_{\mathrm{c}} / \mathrm{H}$ in the range $0.1-0.8$. Fig 7 shows that the effectiveness of the cutoff wall increases with decreasing the ratio $\mathrm{X}_{\mathrm{c}} / \mathrm{H}$ in both homogeneous and heterogeneous scenarios. For relatively small opening sizes $\left(\mathrm{X}_{\mathrm{c}} / \mathrm{H} \leq 0.4\right)$, the reduction achieved by the cutoff wall was lower in case HLH relative to the homogeneous scenario, for an equivalent opening size. For wider opening sizes $\left(\mathrm{X}_{\mathrm{c}} / \mathrm{H}>0.6\right)$, this difference was reversed $\left(\mathrm{L}_{\mathrm{c}} / \mathrm{H}=0.5,1\right)$ or became negligible.

When the wall was located farther away from the coastline boundary $\left(\mathrm{L}_{\mathrm{c}} / \mathrm{H}=2\right)$, its effectiveness increased with increasing the ratio $\mathrm{X}_{\mathrm{c}} / \mathrm{H}$, since at such distance, the cutoff wall 
obstructs the path of the freshwater flow as noted above, thus a wider opening would allow a greater freshwater discharge, and hence more reduction. In such conditions, the seaward discharge in the lower part of the aquifer is further enhanced under the influence of the low $\mathrm{K}$ layer, which explains higher reduction values found in case $\mathrm{HLH}$, for equivalent opening size. Installing the wall at such distance from the coastline is nonetheless not recommended in any case as it leads to negative effect considering the increase of the toe length compared to the case with no wall in place. It is interesting to note that the reduction increased following a polynomial trend in the layered configuration. A similar observation was derived by Luyun et al. (2011) in their homogeneous isotropic setting. For relatively small wall opening $\left(\mathrm{X}_{\mathrm{c}} / \mathrm{H}<0.4\right)$, any slight increase of $\mathrm{X}_{\mathrm{c}} / \mathrm{H}$ led to significant drop in the toe length reduction.

\section{Sensitivity to the hydraulic conductivity contrast ratio and middle layer thickness}
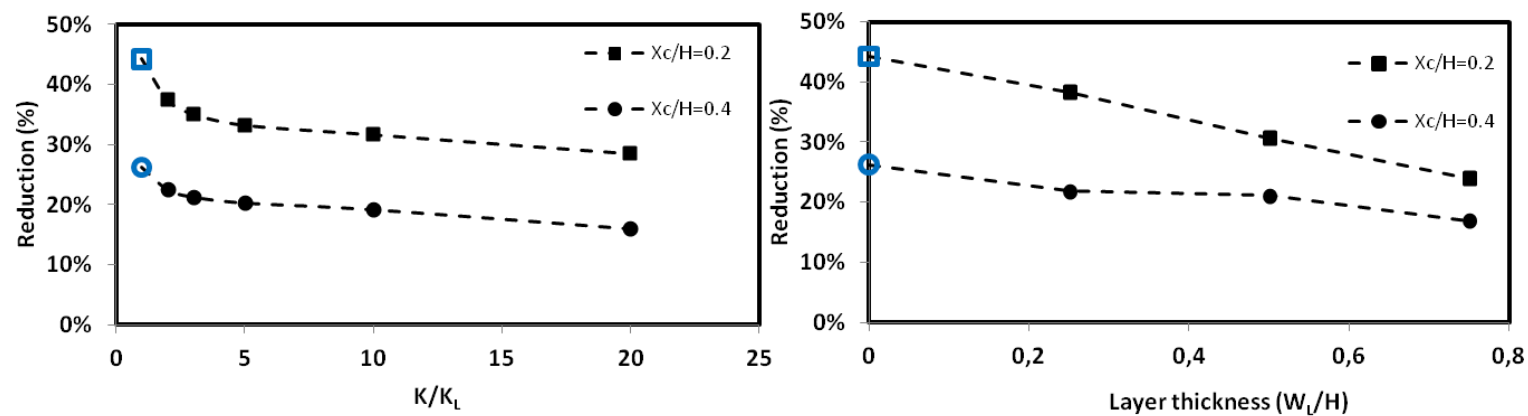

Figure 8 Sensitivity of the reduction to the hydraulic conductivity contrast ratio (left) and to the thickness of the middle layer (right)

The influence of the low K layer was characterised by (1) the hydraulic conductivity contrast between layers and (2) the thickness of the low K layer. The former was characterized by the ratio $\mathrm{K} / \mathrm{K}_{\mathrm{L}}$, where $\mathrm{K}$ is the hydraulic conductivity of the aquifer $(108 \mathrm{~cm} / \mathrm{min})$ and $\mathrm{K}_{\mathrm{L}}$ represents the hydraulic conductivity of the low $\mathrm{K}$ layer, while the latter was characterised by the ratio $\mathrm{W}_{\mathrm{L}} / \mathrm{H}$, where $\mathrm{W}_{\mathrm{L}}$ is the thickness of the low $\mathrm{K}$ layer. The location of the wall was fixed at $\mathrm{L}_{\mathrm{c}} / \mathrm{H}=0.5$, where the cutoff wall was found to exhibit the most reduction. 
The influence of the dimensionless ratio $\mathrm{K} / \mathrm{K}_{\mathrm{L}}$ was explored over the range 1-20. In general, the reduction achieved by the cutoff wall decreased with increasing the ratio $\mathrm{K} / \mathrm{K}_{\mathrm{L}}$ (Fig 8). The blue points represent the reduction achieved by the cutoff wall for $K / K_{L} /=1$, i.e the homogeneous case. For $\mathrm{X}_{\mathrm{c}} / \mathrm{H}=0.2$, the reduction dropped from $44 \%$ for contrast ratio $\mathrm{K} / \mathrm{K}_{\mathrm{L}} /=1$ to $28 \%$ for $\mathrm{K} / \mathrm{K}_{\mathrm{L}} /=20$, and for $\mathrm{X}_{\mathrm{c}} / \mathrm{H}=0.4$, the reductions dropped from $26 \%$ to $16 \%$, as $\mathrm{K} / \mathrm{K}_{\mathrm{L}}$ moved up from 1 to 20 respectively. In other words, the net decrement of $\mathrm{R}$ associated with the increment of $\mathrm{K} / \mathrm{K}_{\mathrm{L}}$ from 1 to 20 was $16 \%$ and $10 \%$, for an opening ratio of 0.2 and 0.4 , respectively.

In such configuration, the change in the effectiveness of the cutoff wall associated with the increment of the ratio $\mathrm{K} / \mathrm{K}_{\mathrm{L}}$ (or the decrement of $\mathrm{K}_{\mathrm{L}}$ ) is attributed to two opposed processes. The first one is the redistribution of the freshwater flow in the lower and upper parts of the aquifer because of the middle low $\mathrm{k}$ layer, leading to more repulsion of the saltwater wedge prior to wall installation. This first process results in an increase in the flow velocity at the opening of the wall and thus is expected to enhance the wall effectiveness. It is interesting to note that this process resulted in the total obstruction of the upper part of the seawater wedge below the middle layer for high ratios $\mathrm{K} / \mathrm{K}_{\mathrm{L}}$, which resulted in a small intrusion in the upper part of the aquifer (Fig 9).

The second factor is the inhibition of the downward freshwater flow from the upper part to the lower part of the aquifer by the middle layer due to its lower K. This second factor will tend to reduce the performance of the cutoff wall. The decreasing trend of the reduction values observed here suggests that that the second process appears to have more influence on the overall performance of the cutoff wall relative to the first in such configurations. 

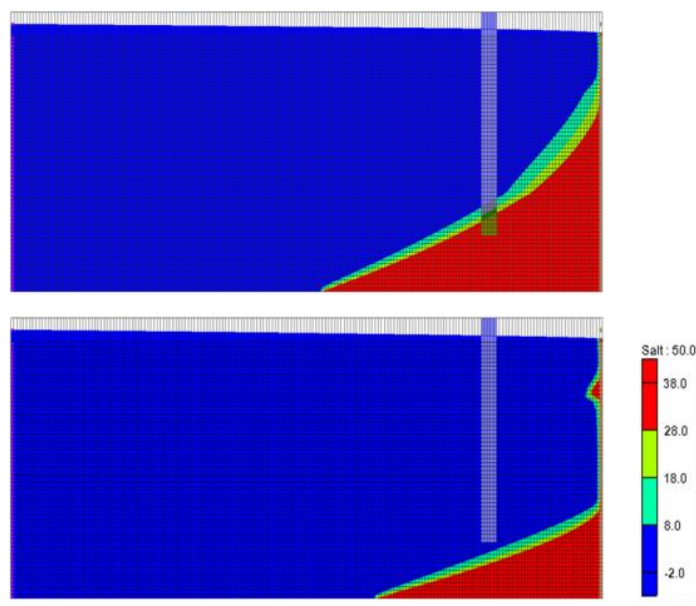

Figure 9 Saltwater wedge prior to wall installation; (top) $K / K_{L}=2$; (bottom) $K / K_{L}=20$. The dark cells indicate the desired position of the wall before construction

The influence of the low $K$ layer thickness was examined for three values of $\mathrm{W}_{L} / \mathrm{H}$, namely $0.25,0.5$ and 0.75 . Fig 8 shows that increasing the thickness of the low K layer reduced the effectiveness of the cutoff wall. The blue points represent the reduction achieved by the cutoff wall for $\mathrm{W}_{\mathrm{L}}=0$, i.e no middle low $\mathrm{K}$ layer (homogeneous aquifer). For $\mathrm{X}_{\mathrm{c}} / \mathrm{H}=0.2$, the percentage reduction went down from $44 \%$ for the homogeneous case down to $24 \%$ for $\mathrm{W}_{\mathrm{L}} / \mathrm{H}$ $=0.75$. The reduction decreases with $\mathrm{W}_{\mathrm{L}} / \mathrm{H}$ in a nearly linear trend. Fig 10 shows that prior to wall installation, the increase of the middle layer thickness induced not only the seaward retreat of the interface, but also a more elongated transition zone widening over the length of the interface, which agrees with results of Lu et al. (2013).

The tip of the wall penetrated into the wedge for $\mathrm{W}_{\mathrm{L}} / \mathrm{H}=0.25$, while it was located into the dispersive zone for $\mathrm{W}_{\mathrm{L}} / \mathrm{H}=0.75$, yielding a reduction in the wall effectiveness to halt the saltwater wedge. For $\mathrm{X}_{\mathrm{c}} / \mathrm{H}=0.4$, the maximum and minimum values were $22 \%$ and $17 \%$, corresponding to a ratio $\mathrm{W}_{\mathrm{L}} / \mathrm{H}$ of 0.25 and 0.75 , respectively. The further decrement of the wall reduction as the low $\mathrm{K}$ layer thickness becomes greater may be because it becomes more difficult for the downward movement of the freshwater and hence the effect of the cutoff wall subsequently weakens. 

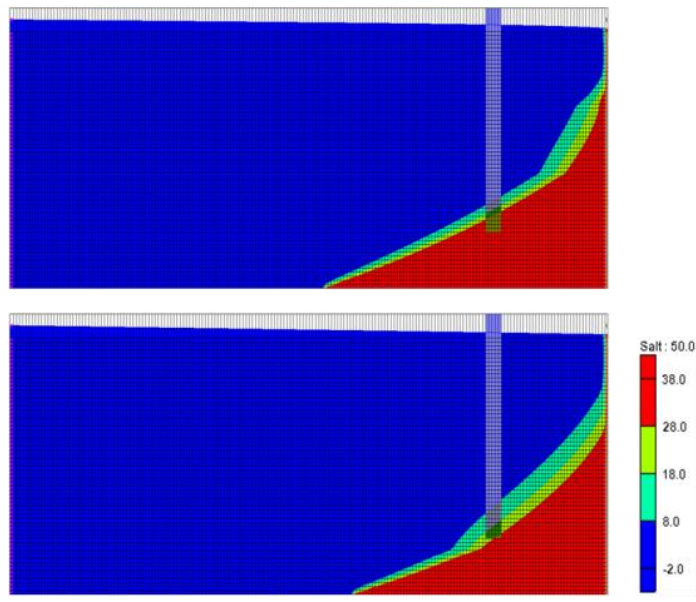

Figure 10 Saltwater wedge prior wall installation; (top) $\mathrm{W}_{\mathrm{L}} / \mathrm{H}$ of 0.25 ; (bottom) $\mathrm{W}_{\mathrm{L}} / \mathrm{H}$ of 0.75 . The dark cells indicate the desired position of the wall before construction

Sensitivity to saltwater density

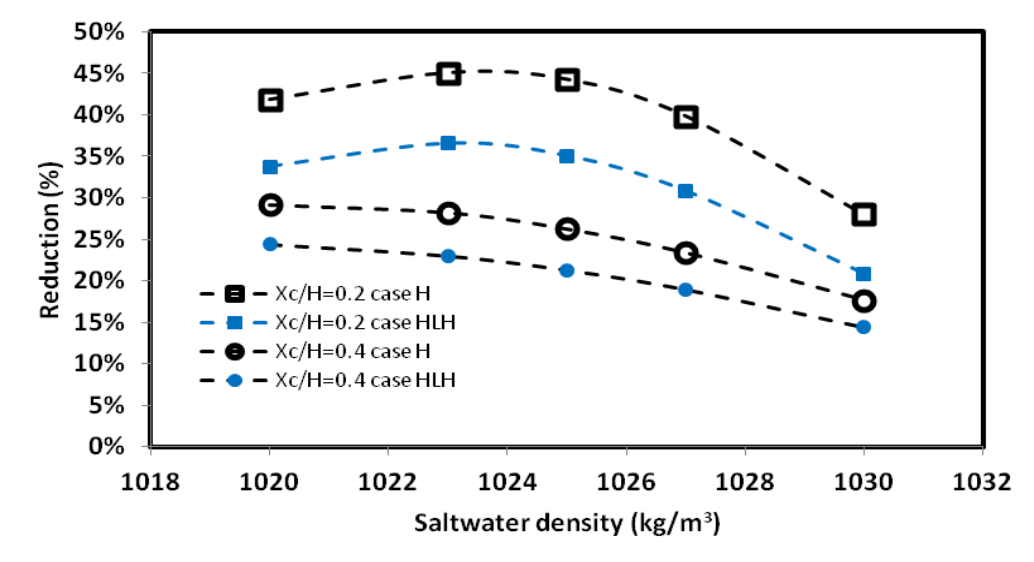

Figure 11 Sensitivity of the reduction to the saltwater density
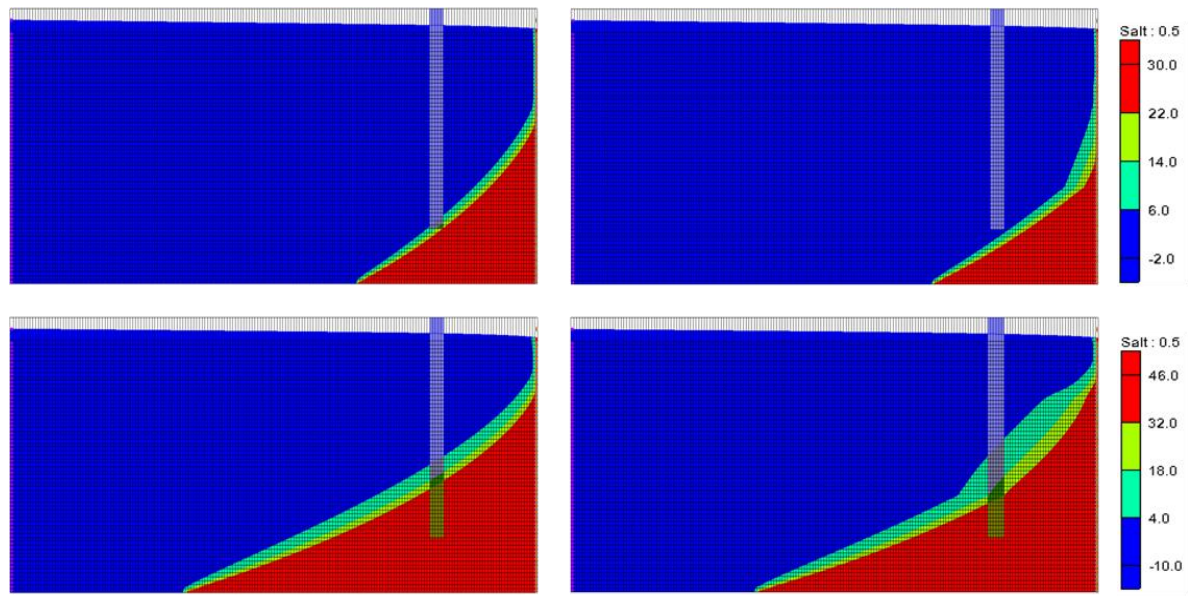

Figure 12 Saltwater wedge prior installation of the wall; (top) $D s=1020 \mathrm{Kg} / \mathrm{m}^{3}$; (bottom) $\mathrm{Ds}=1030 \mathrm{Kg} / \mathrm{m}^{3}$, (left) case $\mathrm{H}$ and (right) case HLH. The dark cells indicate the desired position of the wall before construction 
The influence of the saltwater density was then finally investigated for a typical range of seawater density. The influence of the saltwater density was investigated for a typical range of seawater density $1020-1030 \mathrm{~kg} / \mathrm{m}^{3}$. In overall, the performance of the cutoff wall in reducing the saltwater intrusion length decreased with increasing saltwater density (Fig 11). In all the simulations, the location of the wall was fixed at $\mathrm{L}_{\mathrm{c}} / \mathrm{H}=0.5$ from the saltwater boundary, for the opening ratios $\mathrm{X}_{\mathrm{c}} / \mathrm{H}=0.2$ and 0.4 only.

For the homogeneous case with opening ratio $\mathrm{X}_{\mathrm{c}} / \mathrm{H}=0.2$, the reduction achieved by the cutoff wall ranged from $42 \%$ for seawater density of $1020 \mathrm{~kg} / \mathrm{m}^{3}$ down to $28 \%$, for seawater density of $1030 \mathrm{~kg} / \mathrm{m}^{3}$. For the layered case, the reduction ranged from $34 \%$ to $21 \%$, as the density went up from 1020 to $1030 \mathrm{~kg} / \mathrm{m}^{3}$ respectively. For opening ratio $\mathrm{X}_{\mathrm{c}} / \mathrm{H}=0.4$, the cutoff wall achieved a reduction of $29 \%$ and $18 \%$, in case $\mathrm{H}$; and $24 \%$ and $14 \%$, in case $\mathrm{HLH}$, as the density increased from 1020 to $1030 \mathrm{~kg} / \mathrm{m}^{3}$, respectively. The presence of the low $\mathrm{k}$ layer caused a deviation of the interface, thus partly weakening the effect of the wall on reducing the toe length of the wedge.

Note that for $\mathrm{X}_{\mathrm{c}} / \mathrm{H}=0.2$, the reduction reached maximum values for average density values $\left(1023-1025 \mathrm{~kg} / \mathrm{m}^{3}\right)$ due to the compression effect exerted by the cutoff wall on the saltwater wedge that is stronger than for lower density values, where the extent and thickness of the saltwater wedge are relatively smaller. In any case, as the density further increases $(>1023$ $\mathrm{kg} / \mathrm{m}^{3}$ ), the saltwater of very high concentration invades the spacing between the wall and the coastline. Hence, this high density drives the incursion of the saline water by buoyancy forces through the wall opening and the extension of the wedge on the landward side of the wall (Fig 12), subsequently resulting in a loss of the cutoff wall effectiveness. 


\section{Summary and conclusions}

In this work, we used laboratory experiments and numerical simulations to investigate the effectiveness of cutoff walls in heterogeneous coastal aquifers. Three different aquifer configurations were investigated, including a homogeneous, a stratified aquifer with high $\mathrm{K}-$ low K-high K pattern (HLH) and another stratified aquifer with low K-high K-low K pattern (LHL). The transient intrusion toe length data were experimentally derived from a recently developed automated image analysis method. The SEAWAT code predicted relatively well the transient toe movement over the course of the experiments as well as the overall shape of the saltwater wedge.

The results demonstrated that the cutoff wall was effective in reducing the saline water intrusion length in all the stratified scenarios investigated here, for all hydraulic gradients considered. The stratification imposed a disruption of the flow dynamics, and thus affected the freshwater velocity at the wall opening, thereby altering the performance of the cutoff wall to various degrees, depending on the layering pattern considered. The presence of an underlying low permeability layer (case LHL) was found to obstruct the freshwater flow in the lower part of the aquifer, thereby also substantially locally decreasing the flow velocity at the wall opening, thereby decreasing the repulsion ability of the cutoff wall.

The interlayer of lower permeability exhibited in case HLH was found to affect the downward movement of the freshwater usually associated with the installation of cutoff calls. This resulted in lowering the flow velocity at the wall opening relative to the homogeneous scenario, and thus reducing the repulsion force facing the saltwater. Sensitivity analysis performed in such setting revealed that the cutoff wall was nonetheless able to achieve good reduction of the saline water despite the presence of the low $\mathrm{K}$ layer, especially for smaller opening size and shorter distance between the wall and the coastline. In such configurations, 
the effectiveness of the wall was found to decrease noticeably with decreasing the hydraulic conductivity and thickness of the middle layer as well as saltwater density.

Albeit the stratification patterns found in real field applications may be more complex than the rather simplified and idealised approached adopted herein, our study provides nonetheless for the first time a valuable first-hand insight on the expected impact of layering heterogeneity on the performance of cutoff walls to control SWI. Given that most of the real field sites exhibit prevalently layering stratification patterns, our results emphasizes therefore the necessity to consider ground variability prior to planning and designing of cutoff walls for saltwater intrusion control purposes, for a more realistic assessment of their performance.

\section{Acknowledgements}

The authors wish to thank Queen's University Belfast for supporting the research project through a PhD studentship accorded to the first author. The authors thank the anonymous reviewers for their constructive comments that helped improve the manuscript.

\section{References}

Abarca, E., Clement, T.P., 2009. A novel approach for characterizing the mixing zone of a saltwater wedge. Geophys.Res.Lett. 36(6), L06402.

Abdoulhalik, Antoifi, Ahmed, Ashraf, Hamill, G, 2017. A new physical barrier system for seawater intrusion control. J Hydrol. 549, 416-427.

Anwar, H., 1983. The effect of a subsurface barrier on the conservation of freshwater in coastal aquifers. Water Res. 17, 1257-1265.

Chang, S.W., Clement, T.P., 2012. Experimental and numerical investigation of saltwater intrusion dynamics in flux-controlled groundwater systems. Water Resour.Res. 48, W09527.

Dagan, G., Zeitoun, D.G., 1998. Seawater-freshwater interface in a stratified aquifer of random permeability distribution. J.Contam.Hydrol. 29, 185-203.

Goswami, R.R., Clement, T.P., 2007. Laboratory-scale investigation of saltwater intrusion dynamics. Water Resour.Res. 43, W04418.

Hussain, M.S., Javadi, A.A., 2016. Assessing impacts of sea level rise on seawater intrusion in a coastal aquifer with sloped shoreline boundary. J Hydro-environ Res. 11, 29-41.

Intergovernmental Panel on Climate Change, 2014. Climate Change 2014-Impacts, Adaptation and Vulnerability: Regional Aspects, Cambridge University Press.

Japan Green Resources Agency, 2004. Technical Reference for Effective Groundwater Development.

Kaleris, V.K., Ziogas, A.I., 2013. The effect of cutoff walls on saltwater intrusion and groundwater extraction in coastal aquifers. J Hydrol. 476, 370-383. 
Ketabchi, H., Mahmoodzadeh, D., Ataie-Ashtiani, B., Simmons, C.T., 2016. Sea-level rise impacts on seawater intrusion in coastal aquifers: Review and integration. J Hydrol. 535, 235255.

Lu, C., Chen, Y., Zhang, C., Luo, J., 2013. Steady-state freshwater-seawater mixing zone in stratified coastal aquifers. J Hydrol. 505, 24-34.

Luyun Jr, R.A., 2010. Effects of Subsurface Physical Barrier and Artificial Recharge on Seawater Intrusion in Coastal Aquifers. A dissertation presented to the United Graduate School of Agricultural Sciences, Kagoshima University in partial fulfilment of the requirements for the degree of Doctor of Philosophy http://hdl.handle.net/10232/15057.

Luyun Jr., R., Momii, K., Nakagawa, K., 2009. Laboratory-scale saltwater behavior due to subsurface cutoff wall. J Hydrol. 377, 227-236.

Luyun, R., Momii, K., Nakagawa, K., 2011. Effects of recharge wells and flow barriers on seawater intrusion. Ground Water. 49, 239-249.

McKibbin, R., Tyvand, P.A., 1983. Thermal convection in a porous medium composed of alternating thick and thin layers. Int.J.Heat Mass Transfer. 26, 761-780.

Robinson, G., Hamill, G.A., Ahmed, A.A., 2015. Automated image analysis for experimental investigations of salt water intrusion in coastal aquifers. J Hydrol. 530, 350-360.

Robinson, G., Ahmed, A.A., Hamill, G.A., 2016. Experimental saltwater intrusion in coastal aquifers using automated image analysis: Applications to homogeneous aquifers. J Hydrol. 538, 304-313.

Strack, O.D.L., Stoeckl, L., Damm, K., Houben, G., Ausk, B.K., de Lange, W.J., 2016. Reduction of saltwater intrusion by modifying hydraulic conductivity. Water Resour.Res. 52, 6978-6988.

Sugio, S., Nakada, K., Urish, D.W., 1987. Subsurface seawater intrusion barrier analysis. J. Hydraul. Eng. 113, 767-779.

Voss, C.I., Souza, W.R., 1987. Variable density flow and solute transport simulation of regional aquifers containing a narrow freshwater-saltwater transition zone. Water Resour.Res. 23, 1851-1866.

Werner, A.D., Bakker, M., Post, V.E.A., Vandenbohede, A., Lu, C., Ataie-Ashtiani, B., et al., 2013. Seawater intrusion processes, investigation and management: Recent advances and future challenges. Adv.Water Resour. 51, 3-26. 